(Research ARticle)

\title{
Risk-factors of non-communicable diseases in urban adolescents in Western India
}

\author{
Anushka Marathe, Shailaja Mane *and Sharad Agarkhedkar \\ Dr. D Y Patil Medical College, Hospital and Research Centre of Dr. D Y Patil Vidyapeeth, Pimpri, Pune 18, Maharashtra, \\ India.
}

Publication history: Received on 17 October 2020; revised on 23 October 2020; accepted on 25 October 2020

Article DOI: https://doi.org/10.30574/wjarr.2020.8.2.0394

\begin{abstract}
Adolescents, who were once considered to be the healthiest individuals, are now seeing a rise in NCDs amongst them. This is a Short Term Studentship (STS) Indian Council of Medical Research (ICMR) selected research project of undergraduate medical student. It was done after institutional ethical clearance and permission from School Principal, assent from students and consent from their parents. This is a school based, cross- sectional study of total 200 schoolgoing adolescents of 15 to 17 years age (100 students, each from private and government coed schools) in Urban Pune. A predefined, pretested AACCI lifestyle questionnaire was explained and given to the students followed by physical examination. The overweight and obese students were advised for further investigations for metabolic syndrome. In private school, the mean BMI was 21.16 for boys and 21.13 for girls while in government school, it was 19.62 for boys and 19.58 for girls. In private school, 3\% students were overweight (Girls: 2.22\%, Boys: 3.64\%), 11\% obese (Girls: 6.67\%, Boys: $14.55 \%$ ) and 4\% underweight. In government school, 5\% were overweight (Girls: 6.12\%, Boys: 3.92\%), $3 \%$ obese (Boys: 5.88\%, no girls) and 17\% underweight. In Private School, hypertension was in 5.45\% boys and $2.17 \%$ girls. In government school, hypertension was in $3.64 \%$ boys and $2.17 \%$ girls. The prevalence of risk factors like overweight and obesity was higher in adolescents from private school than government school. It was more in boys in both schools. A significant correlation was found between lifestyle habits like eating fast food, sedentary lifestyle and non-communicable diseases in adolescents. This is due to change in lifestyle habits.
\end{abstract}

Keywords: Adolescents; Overweight; Obese

\section{Introduction}

Adolescents, who were once considered to be the healthiest individuals, have now become a troubled generation. A rise in non-communicable diseases (NCD) among the youth is being seen globally, especially in developing countries like India.

Non-communicable diseases (NCDs) are chronic conditions of non-contagious origin. World Health Organization (WHO) defines an adolescent as any person between 10 and 19 years of age.(1) Adolescence is a tender age when extra care needs to be taken of one's body and mind. The common NCDs in adolescents include hypertension, diabetes, asthma, obesity, cancer, anxiety and depression.

An estimated 1.2 million people under 20 yrs of age die from treatable NCDs each year, accounting for $13 \%$ of global NCD mortality. (2) According to statistics, more than 25\% of obese adolescents had signs of diabetes or impaired glucose tolerance by $15 y$ rs of age in 2013. (3)The prevalence of hypertension is $4.5 \%$ in adolescents. ${ }^{(4)}$ The main reason for the prevalence of the above diseases is change of lifestyle habits. Lack of exercise, consumption of fatty and oily foods, bad food habits, tobacco smoking, alcohol and sedentary lifestyle have led to diseases like hypertension, diabetes, obesity

\footnotetext{
${ }^{*}$ Corresponding author: Dr. Shailaja Mane

Culture Crest, H-7, New Moshi Pradhikaran,Sector No.6,Spine Road, Pune -411039,Maharashtra,India.
} 
and asthma. Lack of awareness on the importance of healthy lifestyle practices is encouraging the youth to adopt bad habits. Variations of NCDs are seen in relation to gender and socio-economic status.

The study was conducted to determine the prevalence and pattern of the major NCDs like hypertension, obesity, diabetes and its risk factors in urban adolescents. This study was useful to identify high risk groups and at-risk lifestyle of various NCDs in adolescents in relation to gender and socio-economic status. With the help of this data, further steps like screening and management can be taken.

\section{Material and Methods}

A school based, Cross sectional study was conducted in a private and a corporate school after its approval from the ethics committee of the institute. Both the schools had coed education, from urban Pune. Permission from the principals of schools and consent from parents and an assent from the students were taken.

Total 200 adolescents of 15 to 17 years (100 each from private and corporate coed schools) were included in the study. Predefined pretested AACCI lifestyle questionnaire for pattern of lifestyle like food habits, exercise, use of media etc. was given.

Inclusion Criteria included Healthy and apparently asymptomatic school going adolescents between 15 to 17 years of age. Exclusion Criteria included adolescents with already preexisting conditions and age group out of the specified range. Adolescents having endocrinal diseases and under treatment like steroids for nephrotic syndrome or, asthma etc. were excluded from the study. The questionnaire was followed by a physical examination for all the students. The overweight and obese students were checked for other conditions like hypertension, vitamin deficiency etc.

Various parameters were recorded like Weight, Height, BP, BMI, Waist Circumference, Hip Circumference, and WaistHip Ratio etc. by using standard techniques. Indian Academy of Pediatrics (IAP) charts were taken as reference for analysis of BMI, height and weight. All the data collected was entered into an Excel sheet. With the help of a statistician and Epi Info 7, statistical analysis was done. The overweight and obese children were referred in the Medical college hospital for basic investigations and further management.

\section{Results and Discussion}

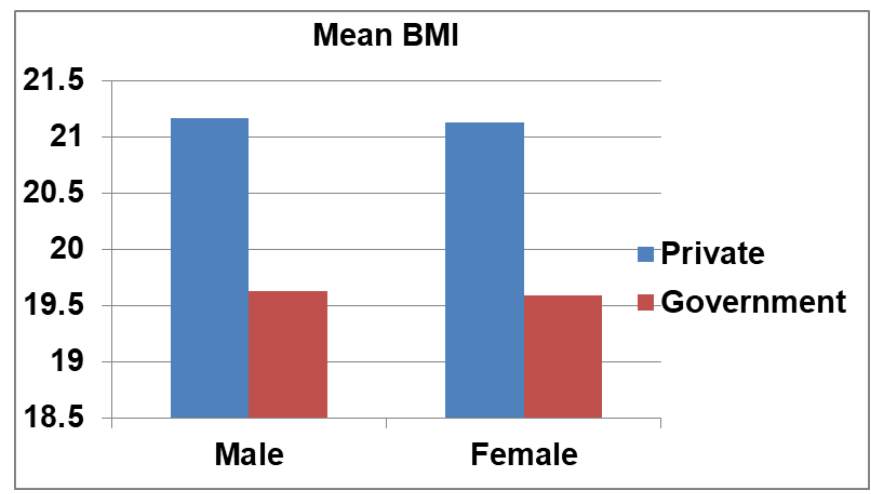

Figure 1 Mean BMI

Table 1 Mean BMI

\begin{tabular}{|l|l|l|}
\hline & Boys & Girls \\
\hline Private & 21.16 & 21.13 \\
\hline Government & 19.62 & 19.58 \\
\hline
\end{tabular}

Mean BMI was higher in private school students than in government school in both boys and girls. 


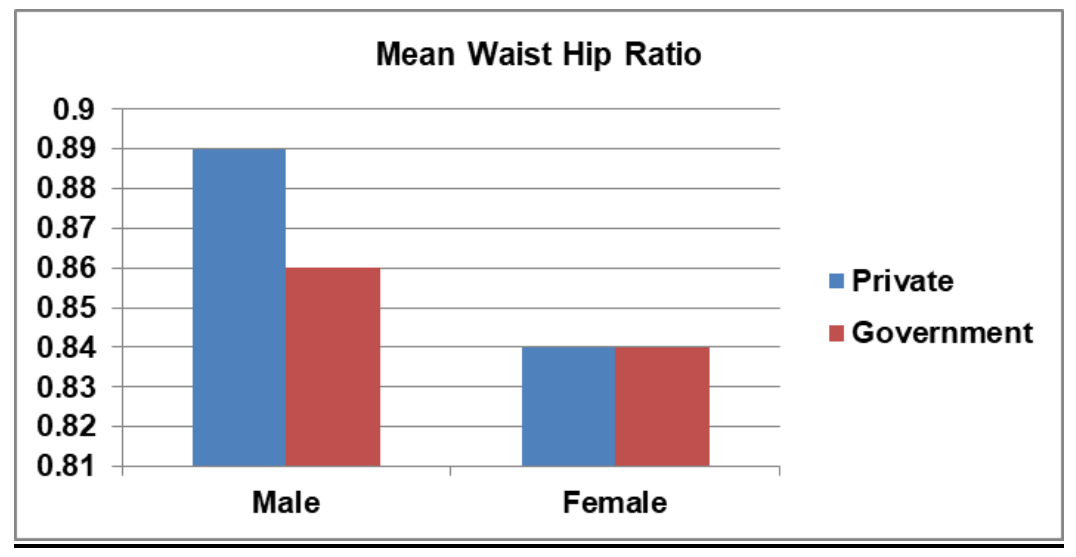

Figure 2 Mean Waist Hip Ratio

Table 2 Mean Waist: Hip Ratio

\begin{tabular}{|l|l|l|}
\hline & Male & Female \\
\hline Private & 0.89 & 0.84 \\
\hline Government & 0.86 & 0.84 \\
\hline
\end{tabular}

Mean waist: hip ratio was higher in boys in private school than in government school and equal in girls in private school and government school.

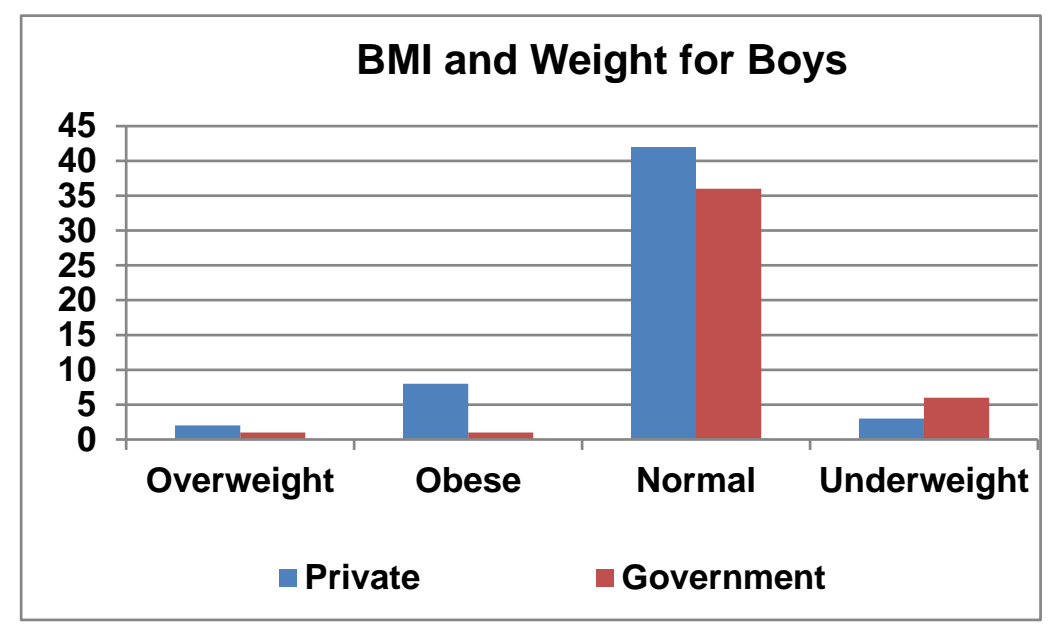

Figure 3 Distribution of Body Mass Index and Weight of Boys

\subsection{Distribution of Body Mass Index and Weight}

Number of overweight girls in government school (6.12\%) is more than in private school (2.22\%). Number of obese girls in private school was $6.67 \%$ but no girl was obese in government school.

In private school, majority of adolescents studied were normal weight $(82.00 \%)$, overweight $(3.00 \%)$, and obese (11.00\%). $2.22 \%$ of girls and 3.64\% of boys were overweight. But $6.67 \%$ of girls and $14.55 \%$ of boys were obese.

In government school, majority of adolescents had normal weight (75.00\%).with overweight (5.00\%), and obese $(3.00 \%)$ students. Total $6.12 \%$ girls and $3.92 \%$ boys were overweight. Among obese students, no girl was obese but $5.88 \%$ boys were obese.

There is a higher percentage of underweight students in government schools (17\%) than in private schools (4\%). 


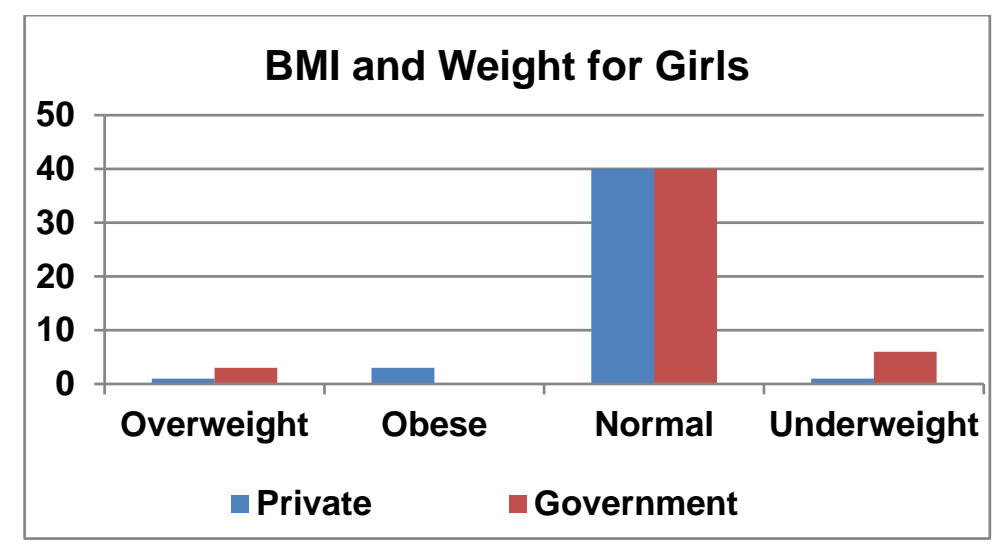

Figure 4 Body mass index and Distribution of BMI/Weight for girls

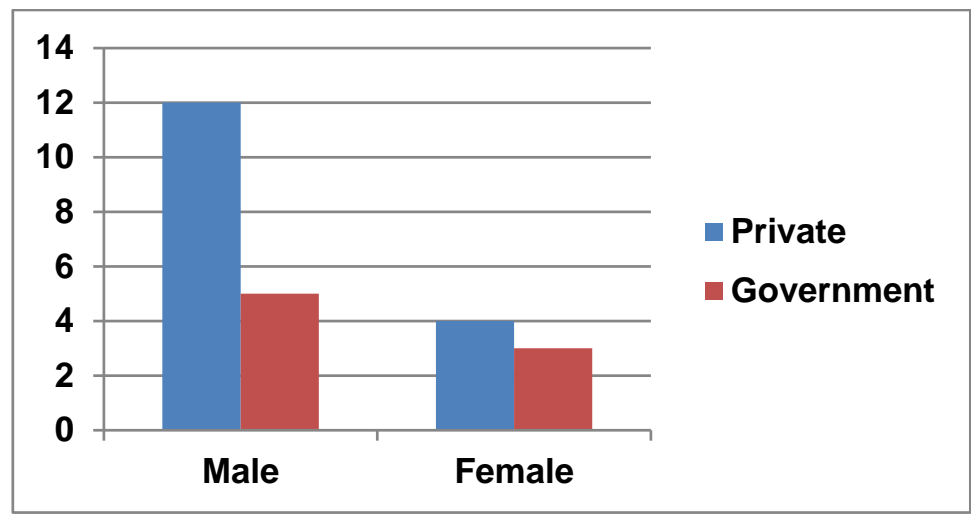

Figure 5 Distribution of High Waist: Hip Ratio

In adolescents from private school, $11.88 \%$ boys had high WHR $(>0.9)$ and $3.96 \%$ girls had high WHR $(>0.84)$. In adolescents from government school, $4.95 \%$ boys had high WHR (>0.9) and $2.97 \%$ girls had high WHR (>0.84). Number of adolescents with high WHR was higher in private school than in government school.

\subsection{Distribution of Lifestyle in boys}

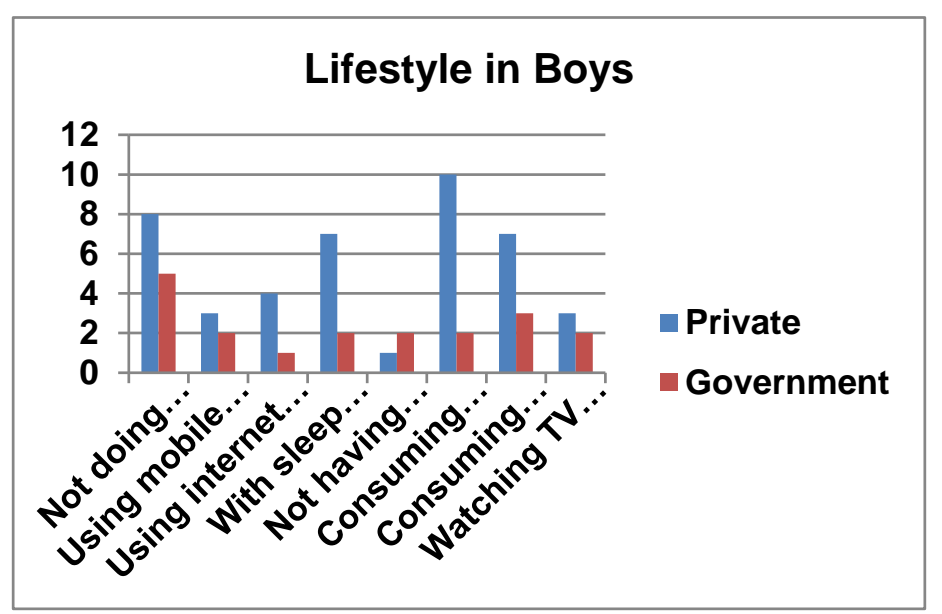

Figure 6 Distribution of Lifestyle Risk Factors in Overweight and Obese Adolescents 
In private school, the number of boys with high BMI not doing physical exercise, using mobile more than 2 hours, using internet for more than 2 hours a day, sleeping less than 8 hours, consuming junk food at-least 1-3 times a week, consuming food in front of Television (TV), watching TV more than 2 hours a day is more than the boys in government school.

\subsection{Distribution of Lifestyle in Girls}

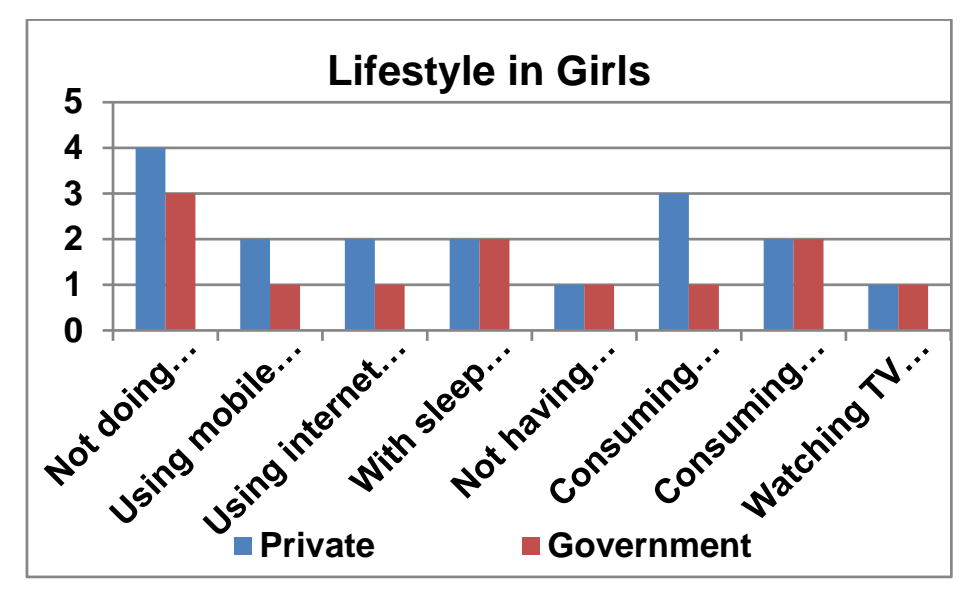

Figure 7 Distribution of Various Lifestyle Risk Factors in Obese and Overweight Adolescents

In private school, the number of girls with high BMI are not doing physical exercise, using mobile more than 2 hours, using internet for more than 2 hours a day. They are consuming junk food at-least 1-3 times a week which is more than the girls in government school.

Among private school students with high BMI, 54.55\% are not doing physical exercise, $22.73 \%$ are using mobile more than 2 hours, $27.27 \%$ are using internet for more than 2 hours a day, $40.91 \%$ are sleeping less than 8 hours, $9.09 \%$ are not taking daily breakfast, $59.09 \%$ are consuming junk food at-least $1-3$ times a week, $40.91 \%$ children consume food in front of TV, $18.18 \%$ watch TV more than 2 hours a day.

In government school students with high BMI, $66.67 \%$ are not doing physical exercise, $25.00 \%$ are using mobile more than 2 hours, $16.67 \%$ are using internet for more than 2 hours a day, $33.33 \%$ are sleeping less than 8 hours, $25.00 \%$ are not taking daily breakfast, $75 \%$ are consuming junk food at-least $1-3$ times a week, $41.67 \%$ children consume food in front of TV, 33.33\% watch TV more than 2 hours a day.

\subsection{Hypertension in Students}

In Private School, the incidence of hypertension in present study was $5.45 \%$ in boys and $2.17 \%$ in girls are hypertensive. In Government School, the incidence of hypertension in present study is $3.64 \%$ boys and $2.17 \%$ girls are hypertensive.

Table 3 Distribution of students with hypertension

\begin{tabular}{|l|l|l|l|}
\hline & Male & Female & Total \\
\hline Private & 3 & 1 & 4 \\
\hline Government & 2 & 1 & 3 \\
\hline
\end{tabular}




\subsection{Association of hypertension with obesity/overweight}

In private school number, amongst the obese and overweight students, hypertension was in $7.14 \%$ and blood pressure was normal amongst $\mathbf{9 2 . 8 6 \%}$ students. In government school, blood pressure was normal in all students (100\%)

Table 4 Number of obese and overweight students with hypertension

\begin{tabular}{|l|l|l|}
\hline & $\begin{array}{l}\text { Obese \overweight with } \\
\text { hypertension (OBeHT) }\end{array}$ & $\begin{array}{l}\text { Obese\ overweight with } \\
\text { Normal BP }\end{array}$ \\
\hline Private & 1 & 13 \\
\hline Government & 0 & 8 \\
\hline
\end{tabular}

\section{Discussion}

In this study, total 100 students from a private school (55 boys and 45 girls), and 100 students from a government school ( 51 boys and 49 girls) were included.

In private school, the number of students with high BMI, not doing physical exercise, using mobile more than 2 hours, using internet for more than 2 hours a day, sleeping less than 8 hours, consuming junk food at-least 1-3 times a week, consuming food in front of TV, screen time was more than 2 hours a day is more than the students in government school.

In private school, the mean BMI was 21.16 for boys and 21.13 for girls. In government school, the mean BMI was 19.62 for boys and 19.58 for girls. Out of 100 adolescents in private school, 12 boys had high WHR ( $>0.9)$ and 4 girls had high WHR (>0.84). Out of 100 adolescents in government school, 5 boys had high WHR (>0.9) and 3 girls had high WHR $(>0.84)$.In Private School, the mean Waist Hip Ratio was 0.89 amongst boys and 0.84 amongst girls. In Government School, the mean Waist Hip Ratio was 0.86 amongst boys and 0.84 amongst girls.

In private school, majority of adolescents studied were normal weight (82.00\%), overweight (3.00\%), and obese (11.00\%), underweight (4.00\%). Among the overweight students $2.22 \%$ were females and $3.64 \%$ were males. Among obese $6.67 \%$ were females and $14.55 \%$ were males.

In government school, majority of adolescents studied were normal weight (75.00\%), overweight (5.00\%), and obese (3.00\%), underweight (17.00\%). Among the overweight students $6.12 \%$ were females and $3.92 \%$ were males. Among obese, none were females and $5.88 \%$ were males.

Mean BMI was higher in the students from private school than in government school in both genders. Similar studies have been carried out in the past.

In 2007, a research was carried out in Ludhiana by Dayanand Medical College and Hospital. In the present study, the prevalence of obesity was $3.4 \%$ and overweight was $12.7 \% .^{(5)}$ Kapil, et al.(6) reported a $7.4 \%$ prevalence of obesity in affluent school children in Delhi whereas Khadilkar, et al.(7) reported a prevalence of obesity to be $5.7 \%$ and overweight 19.9\% among affluent school boys in Pune.

Ramachandran, et al.(8) studied children from six schools in Chennai, two each from high, middle and lower income groups. The prevalence of overweight (including obese) adolescents ranged from $22 \%$ in better off schools to $4.5 \%$ in lower income group schools.

Gupta and Ahmad have also reported that prevalence of sustained hypertension in obese children was 20 times more as compared to controls. ${ }^{(9)}$ Andriska et al. found that $41 \%$ of their hypertensive children were obese.(10) Court et al. have concluded that hypertension has significant correlation with severe childhood obesity.(11)

There are many possible reasons which can explain higher BMI, WHR and waist circumference in adolescents of private school as compared to those from government school. The former has ample quantity of food available as they do not have an economic crisis unlike the latter group. Due to this reason, the government school students tend to eat from home most of the times which is healthy food rather than consuming fast food from outside. International brands and good looking junk foods like potato chips, cream biscuits, etc. are often bought by students of the high strata as they can afford those items. 
Lack of physical activity may be another reason for the difference in the two schools. Both the schools in this study had playgrounds, yet there was a difference in health parameters. Students of well-off families generally travel by car or bus to school unlike the lower strata, who walk or cycle to school. Students of higher economic strata are being introduced to new sedentary activities like video games, $\mathrm{x}$-box, computer games and television. This results in decreased outdoor activities. On the contrary, students from lower social strata don't have many options other than doing household chores or playing outside

Academic focus is increasing day by day with increased competition amongst students. Private school students spend most of their time at tuitions or academic institutes. There is very less time for them to focus on physical activities as it has not been given sufficient importance. There is a lack of awareness on the importance of physical exercise in students and parents as well. According to observations in the study, girls have fewer overweight and obese students compared to boys. It could be due to increased consciousness amongst girls in maintaining their figures or getting zero body figure according to recent trends.

There was a significant number of underweight students in the government school (17\%). Due to cultural issues of favoring the boy child from infancy and gender discrimination of the girl child, adolescent girls are malnourished. This is accompanied with early marriage and teen pregnancy especially in low socio-economic strata families. A malnourished mother produces low birth weight babies. If these small babies put on excessive weight, they are more at risk for metabolic syndrome and NCDs later in life (Barker's hypothesis) ${ }^{(12)}$. Well-nourished girls produce healthy babies. In order to decrease the prevalence of NCDs like obesity and hypertension amongst adolescents, healthy lifestyle and healthy eating habits should be promoted.

There should be a focus on improving healthy habits. Families belonging to lower socio-economic strata should consume healthy foods like fruits (banana) which are cheap and easily available. Physical education should be given importance in schools and at home. Awareness about good eating habits, physical exercise and their relation with NCDs should be spread, to students and their parents. Efforts to increase the awareness about healthy lifestyle in the community particularly in schools must be taken. Tracking of BMI and BP should be done from birth to adolescence in every child. At risk children need to be screened regularly for overweight, obesity and metabolic syndrome. In schools, peer educator groups can be formed which will be useful in this task.

\section{Conclusion}

The prevalence of NCDs like overweight, obesity and hypertension is higher in private school going adolescents than in government school. The incidence was more in boys than in the girls of both the schools. Students with sedentary lifestyle, no exercise, increased consumption of junk food and increased screen time were found to have NCDs. Hence, a significant correlation is present between NCDs and lifestyle factors. This may be due to a change in lifestyle habits like consumption of junk food, reduced physical activity, increased screen time and lack of awareness amongst children and their parents. Early interventions should be done in childhood and adolescence to prevent NCDs in adulthood. Efforts to increase awareness in the community, especially in schools and parents are the need of an hour. A Physical education class should be assigned every day in schools for the students. The role of schools, pediatricians and medical professionals is very important in prevention and early identification of NCDs in adolescents.

\section{Compliance with Ethical standards}

\section{Institutional Ethics committee clearance was taken before starting this study.}

\section{Acknowledgments}

We would like to thank Dr. DY Patil Medical College, Hospital Pune and ICMR (Indian Council of Medical Research) for an opportunity to work on this project. A special thanks to the students, parents and principals of schools for participating in this study.

\section{Disclosure of conflict of interest}

This is an ICMR approved STS project. Authors declare that they have no conflict of interest.

\section{Statement of informed consent}

Written informed assent from students and consent from parents and school principle was taken. 


\section{References}

[1] https://www.who.int/health-topics/adolescent-health/\#tab=tab_1

[2] https://data.unicef.org/topic/child-health/noncommunicable-diseases/

[3] Oxford Textbook of Global Health of Women, Newborns, Children, and Adolescents Ng et Al. 2013.

[4] Pragya Kumar,1 Dhananjay Kumar, $\otimes 2$ Alok Ranjan,3 Chandra Mani Singh,4 Sanjay Pandey,5 and Neeraj Agarwal6 Prevalence of Hypertension and its Risk Factors Among School Going Adolescents of Patna, IndiaJClinDiagn Res. 2017 Jan; 11(1): SC01-SC04.

[5] T Aggarwal 1, R C Bhatia, D Singh, Praveen C SobtiPrevalence of Obesity and Overweight in Affluent Adolescents From Ludhiana, Punjab.IndianPediatr. 2008 Jun;45(6):500-2.

[6] Kapil U, Singh P, Pathak P, Dwivedi SN, Bhasin S. Prevalence of obesity among affluent school children in Delhi. Indian Pediatr 2002; 41: 449- 452.

[7] Khadilkar VV, Khadilkar AV. Prevalence of obesity in affluent school boys in Pune. Indian Pediatr 2004; 41: 857858.

[8] Ramachandran A, Snehalatha C, Vinitha R, Thayyil M, Sathish Kumar CK, Sheeba L, et al . Prevalence of overweight in urban Indian adolescent school children. Diabetes Res ClinPract Practice 2002;57:185-90.

[9] Gupta AK, Ahmad AJ. Normal blood pressure and the evaluation of sustained blood pressure elevation in childhood. Indian Pediatr 1990, 27: 33-42.

[10] Andriska J, Gombik M, Breyer H, Tarr A. Hypertension in children and adolescents: Results of a long term follow up study. ClinExper Theory Practice 1986, A8: 567-579.

[11] Court JM, Hill GJ, Dunlop M, Boulton TJC. Hypertension in childhood obesity.AustPediatr J 1974, 10: 296-300.

[12] Two fifths of pregnant women in India are underweight BMJ 2015; 350 doi(Published 06 March 2015). 